\title{
Gerontology
}

\section{Perception of the Postural Vertical and Falls in Older People}

\author{
Jasmine C. Menant Rebecca J. St George Richard C. Fitzpatrick \\ Stephen R. Lord \\ Neuroscience Research Australia, University of New South Wales, Sydney, N.S.W., Australia
}

\section{Key Words}

Accidental falls · Aged · Vestibular system - Postural

vertical $\cdot$ Balance

\begin{abstract}
Background: Research on the relationship between vestibular function and falls in older people is sparse. The perception of the postural vertical (PPV) provides an indicator measure of vestibular (otolith) function in the absence of visual input and diminished somatosensory feedback. Objective: This study examined whether impaired PPV is associated with falls in this group. Methods: One hundred and ninetyfive people aged 70 plus years stood blindfolded on a motorised platform that could be tilted in the roll plane and attempted to adjust it so that their bodies were aligned to the vertical. Somatosensory feedback was minimised as the base and vertical support surfaces on the tilting platform were covered in thick soft foam rubber. PPV error from true vertical and PPV variability $\left({ }^{\circ}\right)$ were calculated. Participants also underwent an assessment of distal tactile sensitivity and the physiological profile assessment (PPA); fallers were defined as those who had one or more falls during a prospective 12-month follow-up period. Results: Eighty-eight participants (45\%) reported falling in the follow-up year. Increased PPV error and variability were correlated with
\end{abstract}

increased lateral sway in a condition of absent visual input and reduced foot somatosensory feedback (eyes closed/ foam; $r$ range $=0.16-0.20, p<0.05)$ and with composite PPA fall risk scores ( $r$ range $=0.22-0.26, p<0.05$ ). PPV variability was a significant and independent predictor of falls after adjusting for the composite PPA scores, age and gender [adjusted RR $=1.42$ (1.01-1.98)]. Conclusions: Older people with increased PPV variability are at increased risk of falls. These findings indicate that assessment of PPV may augment fall risk assessments in older people.

Copyright $\odot 2012$ S. Karger AG, Basel

\section{Introduction}

Age-related declines in sensory systems that contribute to balance control may increase fall risk in older people. Several measures of vision (visual acuity, depth perception, edge-contrast sensitivity) and somatosensation (lower-limb position sense, foot plantar sensitivity) have been identified as independent predictors of falls in older people $[1,2]$. While tests of vision and somatosensation are commonly incorporated into fall risk assessments [3], clinical assessments of vestibular function are rarely made. This is despite evidence of the high prevalence of vestibular vertigo among people aged over 60 years [4].

\section{KARGER}

Fax +4161306 1234

E-Mail karger@karger.ch

www.karger.com
(C) 2012 S. Karger AG, Basel

0304-324X/12/0586-0497\$38.00/0

Accessible online at:

www.karger.com/ger
Prof. Stephen R. Lord

Neuroscience Research Australia

University of New South Wales

Barker Street, Randwick, NSW 2031 (Australia)

Tel. +61 29399 1061, E-Mail S.Lord@ @eura.edu.au 
Instead, vestibular contribution to balance is often deduced from postural sway tests in which visual and proprioceptive inputs are altered [5-8].

Research on the relationship between vestibular function and falls in older people is sparse and the evidence is controversial. Woolley et al. [9] examined deviations of the 7th cervical vertebra and the head from the vertical immediately following $20^{\circ}$ tilts in roll on a tilt table in 22 blindfolded older people. These measurements of the ability to keep the head vertical [10] correlated significantly with standing balance, walking, and stair ascent and descent ability, but did not discriminate between fallers and non-fallers. Similarly, Brocklehurst et al. [11] did not find associations between vestibular sense, as measured by postural response to a slow tilt and postural sway during quiet stance or falls in a sample of 151 frail older people. Lord et al. [12] also reported no relationship between either performance in Fukuda's vestibular stepping test [13] or a dynamic visual acuity test and postural sway in 95 older intermediate care residents. Furthermore, performance in these vestibular tests did not differ between those who did or did not suffer falls in this frail older group [1] or in a large cohort of community-living older women [2]. The fact that older people with poor balance were not able to complete Fukuda's vestibular stepping test (requiring stepping with feet in place with eyes closed) or the dynamic visual acuity test (requiring walking on a treadmill) might have contributed to these null findings [14].

In contrast, Kristinsdottir et al. [15] reported greater frequency of ocular nystagmus (indicating vestibular asymmetry) following head shaking in older people who had suffered a fall-related hip fracture 12-33 months preceding the assessment or from a fall-related wrist fracture in the previous 8 weeks [16] compared to healthy older controls. In addition, vestibular asymmetry was associated with poorer balance performance assessed with vibration-induced postural sway [15]. Di Fabio et al. [17] also found that instantaneous gain suppression in angular vestibulo-ocular reflex, indicating a deficit in vestibulo-ocular reflex suppression, was associated with falls in the past year among 38 community-dwelling older women. While these findings provide some preliminary evidence that reduced vestibular function is associated with increased risk of falls in older people, sample sizes have been small and the incidence of fall and fractures has only been assessed retrospectively.

The perception of the postural vertical (PPV) appears critical to maintain stability when standing and walking. Although recent research demonstrates the important role played by the somatosensory system to update humans' internal models of verticality $[18,19]$, in the absence of lower limb somatosensory and visual input, PPV is likely primarily modulated by the vestibular system [20]. In fact, Beule and Allum [20] reported that compared with healthy controls, patients with unilateral loss of otolith input showed significantly greater deviations from the vertical when asked to move the support platform on which they stood back to the vertical following forward left and right tilts as well as tilts in the roll plane. In addition, previous research has shown that while young healthy adults can report PPV accurately within a tight 'angle of uncertainty' [21], older people have greater difficulty re-aligning themselves vertically after being tilted [22, 23]. A test of PPV may therefore have utility as part of a fall risk assessment in older people. Given that falls in older people often involve lateral perturbations [24] and that mediolateral sway correlates more significantly with faller status than anterior-posterior sway [25], assessment of PPV following tilts in roll rather than pitch might be more relevant to fall risk in older people. A tilting standing platform with a fixed backboard and all its base and vertical support surfaces covered in thick soft foam rubber would minimise somatosensory feedback from muscle spindles and joint proprioceptors and alter pressure cues and therefore provide a functional assessment of vestibular function whereby the otolith organs would be the primary contributors of PPV.

We hypothesised that: (1) PPV would be correlated with postural sway and a composite physiological fall risk score; (2) older fallers would show less sensitivity (increased absolute error) and/or increased variability in PPV, compared to older non-fallers, and (3) PPV would be associated with an increased risk of future falls in older people. The aims of this study were therefore to assess PPV in roll in older adults and examine further the relationship between PPV and falls.

\section{Methods}

Participants

One hundred and ninety-five older adults (87 males; mean age \pm SD: $77.0 \pm 4.8$ years; age range: $69-90$ years) participated in the study. They all lived independently in the community and were recruited from a larger research study on sensorimotor and neuropsychological risk factors for falls [26]. Inclusion criteria for this study were living in the community, being aged 65 years and over and having a Mini-Mental State Examination score of $\geq 24$ [27]. Exclusion criteria were insufficient English to understand test instructions and being chair fast. In addition, 20 young participants ( 7 men; mean age \pm SD: $29.2 \pm 5.7$ years) reporting no 
medical history of hearing, vestibular, neurological or neuromuscular conditions participated in a test-retest reliability study of the PPV measures. The University of New South Wales Human Research Ethics Committee approved the study protocol, and all participants gave written informed consent before data collection.

\section{Perception of the Postural Vertical}

Experimental Protocol

The participants stood on a servocontrolled motorized platform with a rigid curved backboard that could be rotated about an axis at floor level. The platform enabled the participant to be tilted in roll (mediolateral) with the angle of the ankles remaining constant at a maximal velocity of $1^{\circ} \cdot \mathrm{s}^{-1}$ and with an initial acceleration and a final deceleration of $0.25^{\circ} \cdot \mathrm{s}^{-2}$. While this acceleration was around the threshold of detection of whole-body angular movements by the semi-circular canals $[28,29]$, the platform was returned to the starting position at a random speed different from the initial speed, to minimize temporal cues. We hypothesized that the tilt would be primarily detected by the otolith organs which have threshold accelerations as low as $0.0005 \mathrm{~m} \cdot \mathrm{s}^{-2}$ [30]. The platform position $\left(0.036^{\circ}\right.$ accuracy) was controlled and recorded using a digital position encoder.

To ensure minimal movement of the participant relative to the platform, participants were supported upright in the standing position by means of three large padded straps secured to the backboard at the level of the forehead, sternum and thighs (fig. 1). The back and base of the platform were covered in thick soft foam rubber padding to minimise pressure sense cues. Participants stood barefoot, feet hip-width apart, on soft $15-\mathrm{cm}$ thick foam rubber covering the platform. Extra padding (low density, soft foam) was also placed behind the neck, lower back and lower legs. In this context, participants had to maintain posture against gravity but were not actively engaged in the maintenance of balance. Participants were blindfolded throughout the session. For a given trial, the platform tilted and stopped at a preset position of up to $4^{\circ}$ either right or left of the vertical. Participants used a joystick to adjust the position of the platform until they felt their body was aligned to the vertical. No time constraint was imposed and multiple adjustments were permitted. The encoder error from true vertical was recorded and the platform was repositioned to the vertical before the next trial started. Each session comprised six randomly presented trials, three in each direction. Participants were familiarized with the tilt and operation of the joystick prior to data collection.

To investigate the test-retest reliability of the measurements, the 20 young participants free of vestibular pathology were tested on two occasions, 1 week apart. We based this sample size on a previous study of vestibular function testing [31].

\section{Data Collection and Analysis}

The platform tilt data were collected through the data acquisition card of a desktop computer into custom-written software in LabVIEW (LabVIEW 6.0, National Instruments, Austin, Tex., USA). Data analysis was performed in Microsoft Office Excel (Version 2003, Microsoft Windows). Perceived postural vertical was calculated for each trial as the angle difference $\left(^{\circ}\right)$ between the perceived final position of the platform and true vertical. Perceived postural vertical errors from true vertical (mean of the absolute PPV errors across the six trials) and PPV variability (stan-

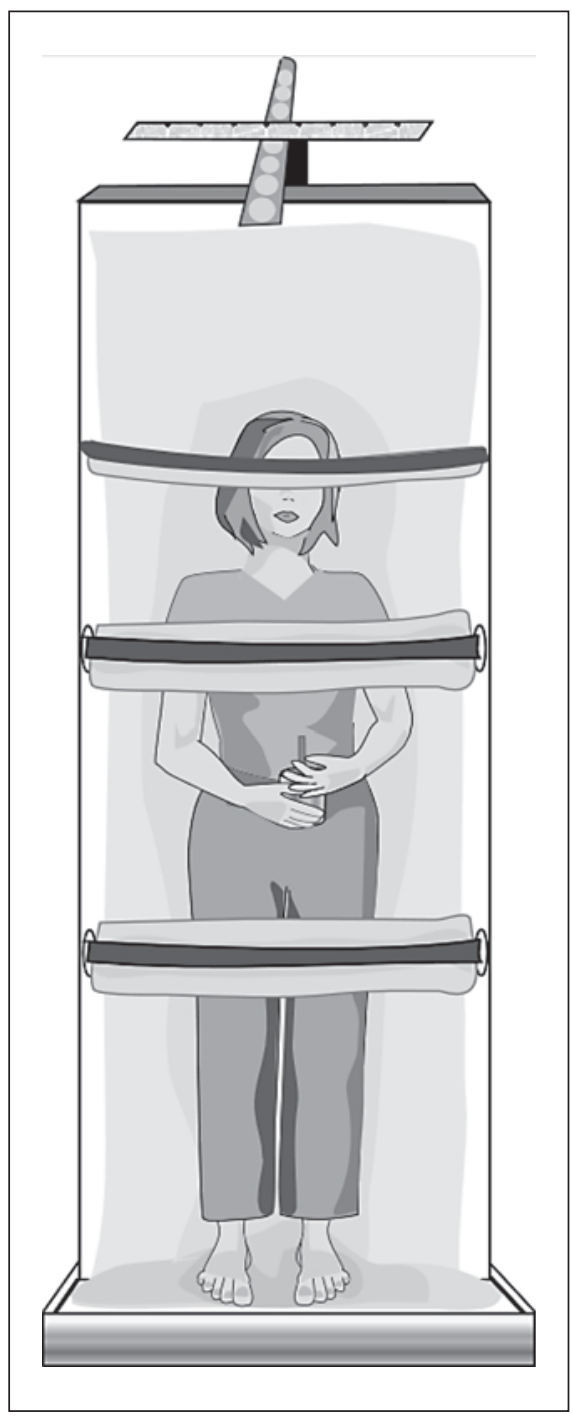

Fig. 1. Experimental set-up for the test of perception of the postural vertical.

dard deviation of the absolute PPV errors across the six trials) were calculated for all subjects. The PPV errors and variability scores were the primary exposure variables of interest and were evaluated in the association with future falls risk, our primary outcome variable.

\section{Sensorimotor Assessment}

Participants were also assessed on the physiological profile assessment (PPA). This comprises five sensorimotor tests, peripheral sensation, visual contrast sensitivity, simple reaction time, lower limb strength and postural sway, which evaluate some key components of human balance control. Descriptions of the apparatus, procedures and test-retest reliability for these tests are reported elsewhere [3]. In brief, proprioception was assessed using a lowerlimb position matching task. The angle of error $\left(^{\circ}\right)$ was measured with a large plastic protractor placed between the legs. The mean 
Table 1. Participants' characteristics and physiological profile assessment (PPA) composite fall risk score for the whole older sample, as well as stratified by faller status

\begin{tabular}{|c|c|c|c|}
\hline Characteristics & $\begin{array}{l}\text { Whole sample } \\
(\mathrm{n}=195)\end{array}$ & $\begin{array}{l}\text { Non-fallers } \\
(\mathrm{n}=107)\end{array}$ & $\begin{array}{l}\text { Fallers } \\
(\mathrm{n}=88)\end{array}$ \\
\hline Male & $87(45)$ & $56(52)$ & $31(35)$ \\
\hline Age, years & $77.0 \pm 4.8$ & $76.5 \pm 4.4$ & $77.7 \pm 5.2$ \\
\hline MMSE score & $27.7 \pm 1.8$ & $27.6 \pm 1.7$ & $27.7 \pm 1.9$ \\
\hline Heart attack/disease & $42(22)$ & $25(23)$ & 17 (19) \\
\hline Arthritis & $112(57)$ & $60(56)$ & $52(59)$ \\
\hline Diabetes & $12(6)$ & $5(5)$ & $7(8)$ \\
\hline Stroke & $5(3)$ & $1(1)$ & $4(5)$ \\
\hline \multicolumn{4}{|l|}{$\geq 2$ falls in the past } \\
\hline 12 months & $28(14)$ & $11(10)$ & $17(19)$ \\
\hline Fear of falling $^{\mathrm{a}}$ & $41(21)$ & $20(19)$ & $21(24)$ \\
\hline$\geq 4$ medications $^{\mathrm{b}}$ & $124(67)$ & $60(61)$ & $64(74)$ \\
\hline PPA score & $0.45 \pm 0.95$ & $0.27 \pm 0.93$ & $0.54 \pm 0.85^{*}$ \\
\hline
\end{tabular}

Data are presented as mean \pm SD or $n(\%) .{ }^{*}$ Indicates statistical significance at $\mathrm{p}<0.05$ between fallers and non-fallers; independent sample t-tests used for continuous variables and $\chi^{2}$ contingency tests for categorical variables. MMSE = Mini-Mental State Examination.

${ }^{a}$ Participants who reported that they were moderately to extremely concerned about falling.

${ }^{\mathrm{b}}$ Data missing for 9 non-fallers and 2 fallers.

error from five trials was recorded. Edge contrast sensitivity (dB) was assessed using the Melbourne Edge Test [32]. Simple reaction time was measured using a hand-held electronic timer with a light as the stimulus and a finger press as a response; the mean of 10 trials was recorded. Isometric knee extension strength was measured while the participant sat with both knee and hip placed at angles of approximately $90^{\circ}$. The best of three maximal isometric contractions of the dominant leg was recorded. Postural sway (path length in $\mathrm{mm}$ squares and medial-lateral distance in $\mathrm{mm}$ ) was recorded using a swaymeter that measured the displacement of the body at the level of the waist as the participants stood quietly barefoot for $30 \mathrm{~s}$ with eyes open and then closed on the floor and on a foam mat $(60 \times 60 \times 15 \mathrm{~cm}$ thick $)$. An individual falls risk score was determined from a weighted regression of the PPA scores. The score has been shown to predict risk of multiple falls in older people with an accuracy up to $75 \%$ [2]. In addition, foot plantar tactile sensitivity was assessed on the dominant foot at the first metatarsal-phalangeal joint using Semmes-Weinstein monofilaments and following a 2-alternative forced-choice protocol [3].

\section{Falls Follow-Up Procedure}

A fall was defined as 'unintentionally coming to the ground or some lower level and other than as a consequence of sustaining a violent blow, loss of consciousness, sudden onset of paralysis as in stroke or an epileptic seizure' [33]. Falling during the 1-year follow-up was monitored with monthly falls diaries and follow-up telephone calls as required [34]. Fallers were defined as those who reported one or more falls in the 1-year follow-up period.

\section{Statistical Analysis}

To permit parametric analysis, variables with positive skewness were $\log _{10}$ - transformed [35]. Test-retest reliability of the PPV variables in the young participants was assessed with intra-class correlation coefficients (ICC) [36]. ICC values above 0.70 have previously been used to identify a test with clinical utility [37]. In the older group, the relationships among PPV variables, sensorimotor function and balance variables were examined with Pearson correlations and with partial correlations adjusting for age. Independent sample t-tests were used to compare PPV variables between genders. Continuous data (PPV error, PPV variability and PPA score) were then dichotomised using the Youden index [38]. The outcome used to derive the optimal cutoff scores was the faller status (faller vs. non-faller). Relative risks for falls for the PPV variables below the criterion identified with the Youden index (worst performance) were calculated. Modified Poisson regression analysis [39] was used to determine whether either PPV variable was an independent predictor of falls, with adjustment for the composite PPA score, age and gender. No adjustments for medical conditions were made as our underlying premise is a functional/physiological one and we maintain that the effects of any medical conditions (diagnosed or not) would be manifest in one or more of the physiological measures assessed [2]. All significance levels were set at $\mathrm{p}<0.05$ and all statistical analyses were performed using SPSS (Version 17.00 for Windows; SPSS Science, Chicago, Ill., USA).

\section{Results}

Table 1 displays the participants' characteristics (whole sample and stratified by faller status).

\section{Reliability of the PPV Measures}

The young normal participants performed the test with minimal error $\left[\mathrm{PPV}\right.$ error $\left(1.01^{\circ} \pm 0.49\right)$ and variability $\left.\left(0.63^{\circ} \pm 0.31\right)\right]$. An independent sample t-test revealed that there was no gender effect in the young sample for any of the PPV variables ( $p>0.05)$. Intra-class reliability analysis indicated the PPV error and variability displayed fair reliability [ $\mathrm{ICC}_{3,1}$ of 0.55 (95\% CI: $0.16-$ 0.79 ) and $\mathrm{ICC}_{3,1}$ of 0.55 (95\% CI: 0.16-0.79), respectively].

\section{$P P V$ and Age and Gender}

In the elderly group, age was significantly correlated with PPV error and variability $(\mathrm{r}=0.306, \mathrm{p}<0.01$ and $r=0.232, p<0.01$, respectively). The older women exhibited significantly greater PPV error than the older men: $1.24^{\circ} \pm 0.74$ versus $0.97^{\circ} \pm 0.51$, respectively $(\mathrm{t}=2.87, \mathrm{p}$ $=0.005)$, and this association remained significant after adjusting for age $\left(\mathrm{F}_{1,192}=13.03, \mathrm{p}<0.001\right)$. PPV variability scores were greater in the women $\left(0.86^{\circ} \pm 0.54\right)$ than in the men $\left(0.70^{\circ} \pm 0.47 ; \mathrm{t}=2.16, \mathrm{p}=0.032\right)$ and this association remained significant after adjusting for age $\left(\mathrm{F}_{1,192}=7.92, \mathrm{p}=0.005\right)$. 


\section{Relationships between the PPV Variables and}

Sensorimotor Function, Sway and Physiological Fall

Risk

As displayed in table 2, increased PPV errors and variability were correlated with high PPA fall risk scores after controlling for age. PPV error and lateral sway correlated more strongly in the condition of both altered foot somatosensory feedback and absent visual input (foam/eyes closed) compared to absent visual input only (floor/eyes closed), suggesting that vestibular changes underlie changes in PPV. Furthermore, PPV variability was significantly associated with lateral sway in the eyes closed/foam condition. There was no association between foot plantar tactile sensitivity and either measure of PPV (PPV error: $\mathrm{r}=$ $-0.084, \mathrm{p}=0.24$; PPV variability: $\mathrm{r}=-0.023, \mathrm{p}=0.75$ ).

\section{PPV and Falls}

Of the 195 older participants, 107 (55\%) reported having no falls in the follow-up year and 88 (45\%) reported one or more falls. Of those who fell, 55 fell once only and 33 fell two or more times. More women (53\%) than men $(36 \%)$ fell in the follow-up year $\left(\chi^{2}=5.72, \mathrm{p}=0.017\right)$.

There were no differences in age or Mini-Mental State Examination scores between the fallers and non-fallers ( $\mathrm{p}=0.070$ and $\mathrm{p}=0.518$, respectively). The unadjusted and adjusted relative risks for PPV error and PPV variability are shown in table 3. Modified Poisson regression revealed that after adjusting for PPA composite scores (PPA scores $>0.30$ ), age and gender, PPV variability was a significant and independent risk factor for falls (likelihood $\chi^{2}=4.17$, d.f. $=1, \mathrm{p}=0.041$ ), but PPV error score was not (likelihood $\chi^{2}=2.51$, d.f. $=1, \mathrm{p}=0.11$ ).

\section{Discussion}

In this study, we found that older people who exhibited increased PPV errors or variability had increased postural sway, increased physiological fall risk and a higher incidence of falls. PPV error and lateral sway correlated more strongly in the condition of both altered foot somatosensory feedback and absent visual input (foam/eyes closed) compared to absent visual input only (eyes closed), suggesting that vestibular changes underlie changes in PPV. In addition, PPV variability was significantly associated with lateral sway in the eyes closed/foam condition, further indicating that vestibular function primarily contributed to PPV precision in this experiment. The finding that PPV variability was an independent predictor of falls after adjusting for PPA fall risk scores, age and gender sug-
Table 2. Correlation coefficients ( $\mathrm{r}$ ) among the sway variables (path and lateral distance), the physiological profile assessment (PPA) composite fall risk score and the perception of the postural vertical (PPV) error and variability in the older group

\begin{tabular}{llll}
\hline Condition & Variable & PPV error & PPV variability \\
\hline Floor/eyes open & sway path $^{\mathrm{a}}$ & 0.04 & 0.06 \\
& lateral sway $^{\mathrm{b}}$ & 0.13 & $0.18^{* \#}$ \\
\hline Floor/eyes closed & sway path $^{\mathrm{a}}$ & 0.05 & 0.01 \\
& lateral sway $^{\mathrm{b}}$ & 0.04 & 0.04 \\
\hline Foam/eyes open & sway path $^{\mathrm{a}}$ & $0.23^{* * \#}$ & $0.25^{* * \#}$ \\
& lateral sway $^{\mathrm{b}}$ & 0.13 & $0.18^{*}$ \\
\hline Foam/eyes closed & sway path $^{\mathrm{a}}$ & 0.14 & 0.13 \\
& lateral sway $^{\mathrm{b}}$ & $0.20^{* *}$ & $0.16^{*}$ \\
\hline & PPA score & $0.26^{* * \#}$ & $0.22^{* * \#}$ \\
\hline
\end{tabular}

* Statistical significance at $\mathrm{p}<0.05$; ${ }^{*}$ statistical significance at $\mathrm{p}<0.01$; ${ }^{*}$ statistical significance at $\mathrm{p}<0.05$ after controlling for age.

${ }^{\text {a }}$ Recorded as the number of millimeter squares crossed by the pen in $30 \mathrm{~s}$.

${ }^{b}$ Recorded as the maximal medial-lateral distance recorded by the pen in $30 \mathrm{~s}$.

${ }^{\mathrm{c}} \mathrm{z}$-score units.

gests that this measure complements the PPA assessments of vision, peripheral sensation, lower limb strength, reaction time and balance performances, and that the inclusion of a simple functional test of vestibular sense may be of benefit in fall risk assessments.

Beule and Allum [20] previously described a test of PPV whereby participants standing on a movable support platform were required to return the platform to the horizontal position following tilts in roll and pitch planes using a joystick. The authors found that patients with unilateral otolith disorders performed worse than healthy agematched controls on this task, and suggested that this test could be used as a simple clinical test of otolith function. However, this set-up allowed participants to use somatosensory feedback from the whole body afferent and motor commands to regain verticality. The tilt-platform used here overcomes this limitation as participants are fixed firmly to a back support and all joint angles important for balance control remain constant throughout the tilts; this set-up thus minimises lower-limb proprioceptive cues and emphasises the need to rely on vestibular information from the otolith organs to return to the upright.

Interestingly, older women had poorer PPV than men. It has been reported that female gender is an independent 
Table 3. Number (\%) of participants in each group, unadjusted and adjusted relative risk of falling (95\% CI) for the perception of postural vertical (PPV) variables

\begin{tabular}{llllll}
\hline Characteristic & Criterion & $\begin{array}{l}\text { Fallers } \\
(\mathrm{n}=88)\end{array}$ & $\begin{array}{l}\text { Non-fallers } \\
(\mathrm{n}=107)\end{array}$ & $\begin{array}{l}\text { Relative risk } \\
(95 \% \mathrm{CI})\end{array}$ & $\begin{array}{l}\text { Adjusted relative risk }^{\mathrm{a}} \\
(95 \% \mathrm{CI})\end{array}$ \\
\hline $\mathrm{PPV}$ error, $\left(^{\circ}\right)$ & $>0.75$ & $65(74)$ & $61(57)$ & $1.55(1.07-2.25)$ & $1.36(0.93-1.99)$ \\
$\mathrm{PPV}$ variability, $\left(^{\circ}\right)$ & $>0.55$ & $59(67)$ & $52(49)$ & $1.54(1.09-2.17)$ & $1.42(1.01-1.98)$ \\
\hline
\end{tabular}

\footnotetext{
${ }^{a}$ After controlling for physiological profile assessment (PPA) composite fall risk scores (PPA scores $>0.30$ ), age and gender.
}

predictor of presence of vestibular vertigo [4]. In addition, early experiments by Witkin et al. [40] found that women performed poorly in the rod and frame test (whereby they aligned a rod further away from the vertical in a tilted frame) and had significantly more difficulty in aligning their tilted chair back to the vertical while viewing a tilted visual field compared to their male counterparts. These authors concluded that women were more visually field-dependent and less able to use vestibular cues to perceive the true upright. A greater prevalence of reduced PPV along with muscle weakness [41] and slower voluntary stepping times [42] might explain the increased rate of falls found here and in many other studies [14, 43, 44].

Recent research provides further evidence that somatosensory information might improve the stability of vertical representation when information from both vestibular and somaesthetic gravitoceptors is congruent [18]. As these cues would only be eliminated in extreme patient cases [45], our PPV test should best be described as a functional rather than a pure measure of vestibular functioning. Nevertheless, considerable care was made to minimise all non-vestibular cues in the PPV tests. Vision was removed by applying a blindfold, ankle alignment was fixed and moved co-axially with the backing board, and contact of the body with the platform was held constant by firm strapping. Participants stood on a thick foam rubber mat and thick soft foam rubber padding was also used to reduce pressure sense cues to minimise input from mechanoreceptors throughout the body when tilting about the mediolateral axis [19]. Further, the lack of significant associations between tactile sensitivity under the first metatarsal-phalangeal joint of the dominant foot and either measure of PPV suggests that foot pressure sensation did not substantially contribute to PPV performance in this experiment.

We acknowledge that the study findings would have been strengthened if the PPV test was assessed for con- current validity against established vestibular tests and that the a posteriori derivation of PPV impairment used in the relative risk analysis might have affected the generalizability of the results. Finally, the test-retest reliability of the PPV test was found to be fair, but as test-retest reliability was assessed in healthy young people who had good PPV, the restricted range of scores at optimal levels may not necessarily be applicable to the older population. Test-retest reliability of the PPV should therefore be performed in a sample of older people to confirm the potential clinical utility of these measures. While the results support the potential benefit of including PPV tests as part of fall risk assessments in older people, the method used here to tilt participants would need to be simplified to make it feasible for use in most clinical settings.

In conclusion, this study demonstrated that PPV measures were significantly associated with postural sway and composite fall risk score in older people. Further, older people with poor PPV were at significantly increased risk of falling and PPV variability was an independent predictor of falls after adjusting for a composite fall risk score based on a battery of sensorimotor and postural sway tests. These findings suggest that a test of PPV may augment fall risk assessments.

\section{Acknowledgments}

Professor Lord is currently an NHMRC Senior Principal Research Fellow.

\section{Disclosure Statement}

This work was funded by the National Health and Medical Research Council (NHMRC) of Australia. The PPA (NeuRA FallScreen) is commercially available through Neuroscience Research Australia. 


\section{References}

$>1$ Lord SR, Clark RD, Webster IW: Physiological factors associated with falls in an elderly population. J Am Geriatr Soc 1991;39:11941200.

$>2$ Lord SR, Ward JA, Williams P, Anstey KJ: Physiological factors associated with falls in older community-dwelling women. J Am Geriatr Soc 1994;42:1110-1117.

3 Lord SR, Menz HB, Tiedemann A: A physiological profile approach to falls risk assessment and prevention. Phys Ther 2003;83: 237-252.

$\checkmark 4$ Neuhauser HK, von Brevern M, Radtke A, Lezius F, Feldmann M, Ziese T, Lempert T: Epidemiology of vestibular vertigo: a neurotologic survey of the general population. Neurology 2005;65:898-904.

$\checkmark 5$ Wolfson L, Whipple R, Derby CA, Amerman P, Murphy T, Tobin JN, Nashner L: A dynamic posturography study of balance in healthy elderly. Neurology 1992;42:2069-2075.

$\checkmark 6$ Black FO, Wall C, Nashner LM: Effects of visual and support surface orientation references upon postural control in vestibular deficient subjects. Acta Otolaryngol 1983;95: 199-201.

$>7$ Horlings CG, Kung UM, Bloem BR, Honegger F, Van Alfen N, Van Engelen BG, Allum $\mathrm{JH}$ : Identifying deficits in balance control following vestibular or proprioceptive loss using posturographic analysis of stance tasks. Clin Neurophysiol 2008;119:23382346.

$>8$ Allum JH, Bloem BR, Carpenter MG, Honegger F: Differential diagnosis of proprioceptive and vestibular deficits using dynamic support-surface posturography. Gait Posture 2001;14:217-226.

$>9$ Woolley SM, Czaja SJ, Drury CG: An assessment of falls in elderly men and women. J Gerontol A Biol Sci Med Sci 1997;52:M80M87.

10 Foley J: Vestibulogenic imbalance. BMJ 1978;1:1244-1246.

-11 Brocklehurst JC, Robertson D, JamesGroom P: Clinical correlates of sway in old age - sensory modalities. Age Ageing 1982; 11:1-10.

- 12 Lord SR, Clark RD, Webster IW: Postural stability and associated physiological factors in a population of aged persons. J Gerontol 1991;46:M69-M76.

13 Fukuda T: The stepping test: two phases of the labyrinthine reflex. Acta Otolaryngol 1959;50:95-108.

14 Lord SR, Sherrington C, Menz HB, Close JCT: Falls in Older People: Risk Factors and Strategies for Prevention, ed 2. Cambridge, Cambridge University Press, 2007.

$\checkmark 15$ Kristinsdottir EK, Jarnlo GB, Magnusson M: Asymmetric vestibular function in the elderly might be a significant contributor to hip fractures. Scand J Rehabil Med 2000;32:5660.
16 Kristinsdottir EK, Nordell E, Jarnlo GB, Tjader A, Thorngren KG, Magnusson M: Observation of vestibular asymmetry in a majority of patients over 50 years with fallrelated wrist fractures. Acta Otolaryngol 2001;121:481-485.

17 Di Fabio RP, Greany JF, Emasithi A, Wyman, JF: Eye-head coordination during postural perturbation as a predictor of falls in community-dwelling elderly women. Arch Phys Med Rehabil 2002;83:942-951.

18 Barra J, Marquer A, Joassin R, Reymond C, Metge L, Chauvineau V, Pérennou D: Humans use internal models to construct and update a sense of verticality. Brain 2010;133: 3552-3563.

19 Bringoux L, Nougier V, Barraud PA, Marin L, Raphel C: Contribution of somesthetic information to the perception of body orientation in the pitch dimension. Q J Exp Psychol A 2003;56A:909-923.

20 Beule AG, Allum JHJ: Otolith function assessed with the subjective postural horizontal and standardised stance and gait tasks. Audiol Neurootol 2006;11:172-182.

-21 Mann CW, Berthelot-Berry NH, Dauterive HJ Jr: The perception of the vertical; visual and non-labyrinthine cues. J Exp Psychol 1949;39:538-547.

22 Bisdorff AR, Wolsley CJ, Anastasopoulos D, Bronstein AM, Gresty MA: The perception of body verticality (subjective postural vertical) in peripheral and central vestibular disorders. Brain 1996;119:1523-1534.

23 Mazibrada G, Tariq S, Perennou D, Gresty M, Greenwood R, Bronstein AM: The peripheral nervous system and the perception of verticality. Gait Posture 2008;27:202-208.

24 Topper AK, Maki BE, Holliday PJ: Are activity-based assessments of balance and gait in the elderly predictive of risk of falling and/or type of fall? J Am Geriatr Soc 1993;41:479-487.

25 Maki BE, Holliday PJ, Topper AK: A prospective study of postural balance and risk of falling in an ambulatory and independent elderly population. J Gerontol 1994;49:M72M84.

26 Anstey KJ, Wood J, Kerr G, Caldwell H, Lord SR: Different cognitive profiles for single compared with recurrent fallers without dementia. Neuropsychology 2009;23:500-508.

-27 Tombaugh TN, McIntyre NJ: The MiniMental State Examination: a comprehensive review. J Am Geriatr Soc 1992;40:922-935.

28 Benson AJ, Hutt EC, Brown SF: Thresholds for the perception of whole body angular movement about a vertical axis. Aviat Space Environ Med 1989;60:205-213.

29 Clark B, Stewart JD: Effects of angular acceleration on man: thresholds for the perception of rotation and the oculogyral illusion. Aerosp Med 1969;40:952-956.

30 Meiry JL: The vestibular system and human dynamic space orientation. Washington, NASA Editor, 1966.
31 Maes L, Vinck BM, De Vel E, D’haenens W, Bockstael A, Keppler H, Philips B, Swinnen F, Dhooge I: The vestibular evoked myogenic potential: a test-retest reliability study. Clin Neurophysiol 2009;120:594-600.

32 Verbaken JH, Johnston AW: Population norms for edge contrast sensitivity. Am J Optom Physiol Opt 1986;63:724-732.

33 Gibson M, Andres R, Isaacs B, Al E: The prevention of falls in later life. A report of the Kellogg International Work Group on the Prevention of Falls by the Elderly. Dan Med Bull 1987;34(suppl 4):1-24.

34 Lamb SE, Jorstad-Stein EC, Hauer K, Becker C, Prevention of Falls Network Europe and Outcomes Consensus Group: Development of a common outcome data set for fall injury prevention trials: the Prevention of Falls Network Europe consensus. J Am Geriatr Soc 2005;53:1618-1622.

35 Tabachnick BG, Fidell LS: Using Multivariate Statistics, ed 5. Amsterdam, Elsevier, 2007.

36 Shrout PE, Fleiss JL: Intraclass correlations: uses in assessing rater reliabillity. Psychol Bull 1979;86:420-428.

37 Streiner DL, Norman G: Health Measurement Scales: A Practical Guide to Their Development and Use. New York, Oxford University Press, 2003.

38 Ruopp MD, Perkins NJ, Whitcomb BW, Schisterman EF: Youden Index and optimal cut-point estimated from observations affected by a lower limit of detection. Biom J 2008;50:419-430.

39 Zou G: A modified poisson regression approach to prospective studies with binary data. Am J Epidemiol 2004;159:702-706.

40 Witkin HA, Lewis HB, Hertzman M, Machover K, Meissner PB, Wapner S: Personality through Perception. New York, Harper, 1954.

41 Vandervoort AA, McComas AJ: Contractile changes in opposing muscles of the human ankle joint with aging. J Appl Physiol 1986; 61:361-367.

-42 Lord SR, Fitzpatrick RC: Choice stepping reaction time: a composite measure of falls risk in older people. J Gerontol A Biol Sci Med Sci 2001;56:M627-M632.

43 Bongue B, Dupré C, Beauchet O, Rossat A, Fantino B, Colvez A: A screening tool with five risk factors was developed for fall-risk prediction in community-dwelling elderly. J Clin Epidemiol 2011;64:1152-1160.

44 Campbell AJ, Borrie MJ, Spears GF: Risk factors for falls in a community-based prospective study of people 70 years and older. J Gerontol 1989;44:M112-M117.

45 Day BL, Cole J: Vestibular-evoked postural responses in the absence of somatosensory information. Brain 2002;125:2081-2088. 